\title{
AVALIAÇÃO DA AÇÃO CICATRIZANTE DA GUAÇATONGA (Casearia sylvestris Sw.) EM FERIDAS EXPERIMENTALMENTE INDUZIDAS EM CAMUNDONGOS
}

\author{
ALVES, José Edgard de Oliveira ${ }^{1}$ \\ MEDEIROS, José Augusto Piedade de ${ }^{2}$ \\ CATELLI, Marcelo Flores ${ }^{3}$
}

\begin{abstract}
RESUMO A guaçatonga (Casearia sylvestris Sw.) tem longa história na tradição popular e amplo espectro de aplicação na medicina folclórica brasileira, sendo utilizada para diversos fins, como analgésico, anti-inflamatório, antiviral, anti-ulceroso e hemostático em lesões de pele e mucosas. O presente estudo teve como objetivo avaliar a eficácia do tratamento tópico com soluções de Casearia sylvestris Sw. em lesões de pele experimentalmente induzidas em camundongos. Foram utilizados 15 animais aleatoriamente distribuídos em 3 grupos: GC (tratados com solução fisiológica), G1\% (tratados com solução de guaçatonga a 1\%) e G10\% tratados com solução de guaçatonga a $10 \%$ ). As feridas foram avaliadas e mensuradas nos dias 1, 4, 6, 8 e 13 após a indução das lesões. Não foram observadas diferenças estatísticas entre os tratamentos, todavia, observou-se cicatrização completa das feridas no grupo G1\% em um prazo menor que os demais, o que sugere que o tratamento com guaçatonga a $1 \%$ apresente maior tendência à promoção da cicatrização. Novos estudos avaliando os efeitos de diferentes concentrações da planta em uma população maior de animais são necessários para melhor entendimento dos efeitos da Casearia sylvestris Sw. sobre o processo de cicatrização.
\end{abstract}

Palavras-chave: Reepitelização. Fitoterapia. Farmacologia.

\section{ASSESSMENT OF HEALING ACTION OF GUAÇATONGA (Casearia sylvestris Sw.) ON EXPERIMENTAL INDUCED WOUNDS IN MICE}

\begin{abstract}
SUMMARY: Guaçatonga (Casearia sylvestris $\mathrm{Sw}$.) has long history in popular traditions and a large spectrum of action on Brazilian folk medicine, applied to several uses, such as analgesic, anti-inflammatory, antiviral, anti-ulcer and haemostatic in injuries on skin and mucous. This study has as aim to evaluate efficacy of topic treatment using Casearia sylvestris $\mathrm{Sw}$. solutions in skin wounds experimentally induced on mice. Were used 15 animals randomly distributed to 3 groups: GC (treated with physiologic solution), G1\% (treated with solution of guaçatonga to $1 \%$ ) and G10\% (treated with solution of guaçatonga to 10\%). The wounds were assessed and measured on days 1, 4, 6, 8 and 13 after induction of the injuries. Do not were observed statistical differences between the treatments, however, was observed complete cicatrization of wounds on group G1\% in a smaller period than on the other groups, that suggests which the treatment with solution of guaçatonga to $1 \%$ has a higher tendency to promote healing of injuries. Are needed further studies assessing the effects of different concentrations of this plant in a larger animal population to improve understanding of the effects of Casearia sylvestris Sw. over the healing process.
\end{abstract}

Keywords: Reepithelization. Phytoterapy. Pharmacology.

\section{INTRODUÇÃO}

A pele é o maior órgão do corpo e é dotada de importantes funções, tais como proteção e barreira contra agentes nocivos e termorregulação, que contribuem diretamente para a manutenção da homeostase e da saúde (FOSSUM, 2008). Uma lesão na pele é caracterizada pela interrupção da continuidade da proteção corporal que deixa o tegumento subjacente, normalmente

\footnotetext{
${ }^{1}$ Residente de Anestesiologia em Pequenos Animais da Universidade Estadual do Norte Fluminense

${ }^{2}$ Médico Veterinário Autônomo

${ }^{3}$ Professor da Universidade Severino Sombra
} 
estéril, exposto a qualquer tipo de contaminação (WALDRON; TREVOR, 1993; FERREIRA, 2005; BEHEREGARAY et al., 2014). A cicatrização de uma lesão por primeira intenção ocorre quando há intervenção médica forçando sua união de maneira mecânica através de suturas. Quando ocorre por segunda intenção, a cobertura do ferimento é feita por migração de células epiteliais para o centro da ferida. A cicatrização por terceira intenção é aquela que ocorre quando a ferida é mantida aberta por um determinado período, sendo posteriormente suturada (WALDRON; TREVOR, 1993; FERREIRA, 2005).

A Casearia sylvestris Swartz, 1860, popularmente conhecida como guaçatonga, tem longa história na tradição popular brasileira, onde apresenta um enorme espectro de atuação. O gênero Casearia possui quase 180 espécies e pertence à família Salicaceae, um desmembramento da extinta família Flacourtiaceae, que possuía 89 gêneros e 1300 espécies distribuídas em países de regiões tropicais e temperadas (FERREIRA et al., 2011). Diversos estudos têm destacado a importância dos extratos e compostos isolados a partir da Casearia sylvestris Sw., ressaltando um importante arsenal farmacoterapêutico para esta planta, reforçando os relatos de seus usos na medicina tradicional e incentivando novas pesquisas visando uma melhor compreensão de seus compostos bioativos e suas bioatividades (FERREIRA et al., 2011).

A estrutura química da Casearia sylvestris Sw. é bastante complexa. Suas folhas contêm fitoquímicos (diterpenos) com ação antitumoral, antifúngica, antibiótica e sua ação antiinflamatória foi considerada similar à do piroxicam e meloxicam em ratos (SASSIOTO et al., 2004). A casearina, outro princípio ativo da Casearia sylvestris Sw. tem atividade antitumoral (KULCHETSCKI et al., 2006). Outros estudos relataram também sua eficácia na redução de níveis séricos de triglicerídeos em ratos (WERLE et al., 2009) e expressiva atuação na inibição do desenvolvimento de fungos e protozoários (TORRES; YAMAMOTO, 1986).

Diante das evidências de benefícios empíricos no uso da guaçatonga e da carência de estudos que validem cientificamente seus efeitos, o presente estudo teve como objetivo avaliar a eficácia de solução obtida a partir da decocção de folhas de Casearia sylvestris Swarts, 1860, no tratamento tópico de lesões de pele experimentalmente induzidas em camundongos.

\section{MATERIAL E MÉTODO}

Foram utilizados 15 camundongos Mus musculus, machos, provenientes do biotério da Universidade Severino Sombra, com peso médio de $75 \mathrm{~g}$ e idade aproximada de 120 dias.

Os animais foram aleatoriamente distribuídos em três grupos com 5 animais, que receberam os seguintes tratamentos: GC (grupo controle), que recebeu $1 \mathrm{ml} / \mathrm{dia}$ de solução fisiológica $(\mathrm{NaCl}$ 0,9\%); G1\%, que recebeu o tratamento com $1 \mathrm{ml} /$ dia Casearia sylvestris $\mathrm{Sw}$. na 
concentração de 1\%; e G10\%, que foi tratado com $1 \mathrm{ml} /$ dia de Casearia sylvestris Sw. a $10 \%$.

Todas as soluções foram administradas topicamente sobre as feridas na quantidade de 1 $\mathrm{ml} /$ dia durante 13 dias.

Para indução dos ferimentos, os animais foram anestesiados com uma associação de cloridrato de cetamina $(5 \mathrm{mg} / \mathrm{kg})$ e cloridrato de xilazina $(2 \mathrm{mg} / \mathrm{kg})$ por via intraperitoneal. A região dorsal foi devidamente tricotomizada e, com o auxílio de uma pinça Kelly nº 12 e uma tesoura cirúrgica romba $\mathrm{n}^{\circ} .14$, foi feita a incisão com retirada de um fragmento de pele de $2 \mathrm{~cm}^{2}$. O ferimento não foi suturado ou coberto por curativo.

Uma folha de acetato foi utilizada para traçar as bordas das lesões e avaliar macroscopicamente a retração e reepitelização das feridas nos dias 1, 4, 6, 8 e 13 do pósoperatório. As imagens foram digitalizadas e analisadas utilizando o software Image J, sendo a reepitelização da ferida estimada pela diferença entre a área total da lesão e a área da lesão ainda descoberta por neoepiderme. A área reepitelizada foi expressa como a porcentagem da área de lesão após os dias da indução do ferimento.

Os dados foram analisados pelo Teste $t$ de Student com grau de confiabilidade de $95 \%$ $(p<0,05)$. O resultados foram expressos como a média \pm o erro padrão da média (EPM).

Após o término dos experimentos, os animais foram eutanasiados de acordo com as normas da American Veterinary Medical Association (AVMA), utilizando-se $25 \mathrm{mg} / \mathrm{kg}$ de tiopental sódico por via intracardíaca com posterior administração de cloreto de potássio pela mesma via. Toda a metodologia foi aprovada pela Comissão de Ética no Uso de Animais da Universidade Severino Sombra, sob protocolo 32/2012.

\section{RESULTADO E DISCUSSÃO}

O camundongo Mus musculus da linhagem suíço albino foi o animal escolhido devido à facilidade de aquisição e manipulação, tamanho (pequeno porte), facilidade em sua acomodação e por ser resistente às agressões cirúrgicas e aos processos infecciosos e com baixa mortalidade (MARCHINI et al., 1988). Foram utilizados camundongos machos, pois, segundo Teves et al. (1986) variações dos ciclos hormonais das fêmeas poderiam interferir no mecanismo do processo de reparação tecidual.

A cicatrização por segunda intenção ou epitelização é um método muito utilizado para o fechamento de feridas em medicina veterinária (PAVLETIC, 2010), sendo, por este motivo, o tipo de cicatrização escolhido para avaliação em nossos estudos. Segundo Birchard e Sherding (2013), uma ferida com clara contaminação, infecção já estabelecida, perda de tecido e deiscência de suturas deve ser mantida aberta durante seu tratamento e reparação dos tecidos. Todavia, 
apesar de em nossos ensaios os animais não apresentarem contaminação nem infecção, as feridas foram mantidas abertas para a validação do fitoterápico na cicatrização por segunda intenção (figura 1).

Figura 1. Imagem digitalizada dos tamanhos das feridas durante as avaliações realizadas analisadas com software Image $\mathbf{J}$.
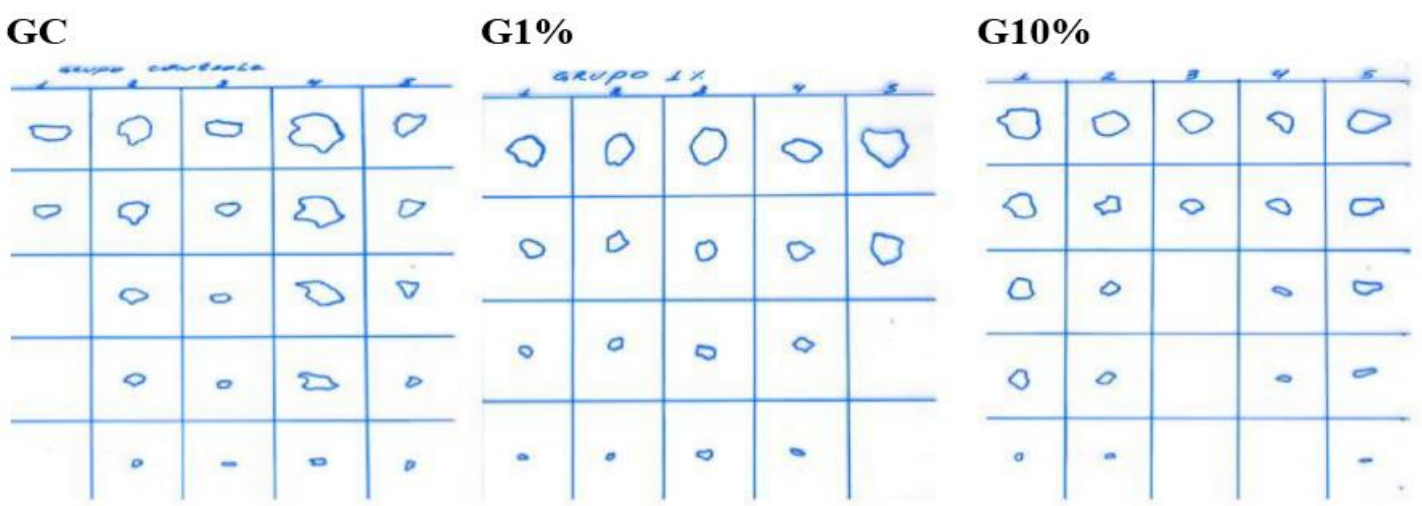

Legenda: GC: Grupo controle; G1\%: Grupo Casearia sylvestris em solução a 1\%; e G10\%: Casearia sylvestris em solução a $10 \%$.

De todos os grupos estudados, o grupo G1\% (Casearia sylvestris Sw. a 1\%) foi o que apresentou resultados mais promissores com relação a eficiência na cicatrização das feridas, mostrando contínua redução da lesão durante toda a avaliação (Gráfico 1). Contudo, as análises estatísticas executadas não apontaram diferenças entre estes valores, fato que atribuímos ao número reduzido de animais utilizados nos grupos experimentais. Ainda assim, nossos resultados mostram tendência a uma cicatrização mais eficiente com o uso da guaçatonga durante o tratamento, mas são discordantes daqueles encontrados por Lipinski (LIPINSKI, 2008), que descreveu que a guaçatonga apresenta efeito cicatrizante em bovinos somente nos dois primeiros dias após a lesão.

Gráfico 1. Médias percentuais de redução das feridas nos grupos experimentais.

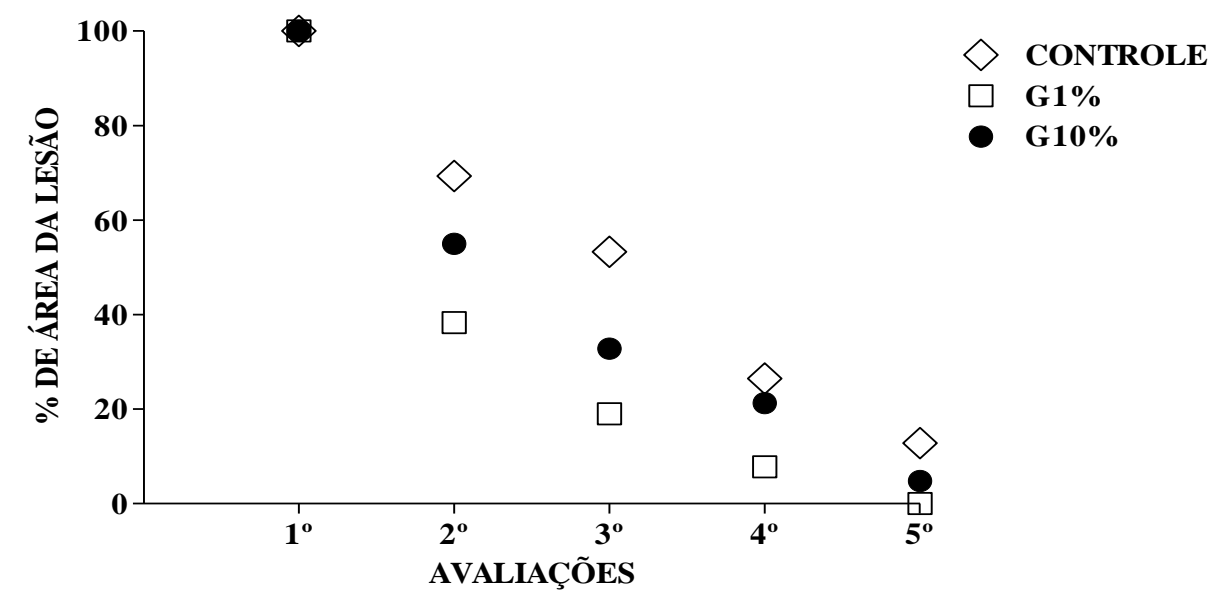

Legenda: G1\%: Grupo tratado com Casearia sylvestris em solução a 1\%; G10\%: Grupo tratado com Casearia sylvestris $\mathrm{Sw}$. em solução a $10 \%$. 
Em G10\%, observamos uma acentuada hiperemia logo após a aplicação do decocto nos primeiros dias. Esses achados foram semelhantes aos resultados obtidos por Lipinski (2008). Observamos que G10\% apresentou uma menor tendência em retração das feridas quando comparado a G1\% durante todo o experimento, sendo, porém, ambos superiores ao grupo controle em todas as avaliações. Albano et al. (2013), citam um pronunciado efeito antioxidante e anti-inflamatório com o uso da Casearia sylvestris $\mathrm{Sw}$. em modelos experimentais, o que sugere que seus constituintes podem causar estes efeitos primariamente por redução da migração celular e da ativação de enzimas relacionada ao processo inflamatório agudo. A Casearia sylvestris Sw. tem mostrado possuir constituintes que alteram a relação $\mathrm{Na}+\mathrm{K}+-\mathrm{ATPase}$ e inibem a atividade da enzima fosfolipase A2, que tem papel importante na inflamação (MATTOS et al., 2007).

É importante ressaltar que ainda não há relatos de toxicidade por uso da Casearia sylvestris. Estudos avaliando a toxicidade da guaçatonga concluíram que o uso do extrato hidroetanólico da planta pode ser seguro mesmo quando feito por longo período (AMENI et al., 2015). Entretanto, ainda não se tem informação com relação às interações farmacológicas que os fitoquímicos possam apresentar frente a outros medicamentos, o que torna importante o aprofundamento dos estudos sobre as propriedades farmacológicas da planta.

Os resultados apresentados no gráfico 1 sugerem que a guaçatonga a $1 \%$ apresentou maior tendência à cicatrização por segunda intenção de feridas experimentalmente induzidas em camundongos, sendo esta a concentração mais eficaz, uma vez que houve cicatrização total em menor prazo quando comparamos aos efeitos obtidos no tratamento com guaçatonga a $10 \%$. Esses resultados sugerem que a relação concentração-efeito não ocorre de maneira diretamente proporcional ou linear, sendo, portanto, necessários estudos que esclareçam melhor as propriedades farmacocinéticas e farmacodinâmicas do fitoterápico.

\section{CONCLUSÃO}

Os resultados mostram uma tendência em aceleração da cicatrização através do uso tópico de Casearia sylvestris Sw., especialmente quando utilizada na solução de $1 \%$, em feridas induzidas experimentalmente em camundongos. Novos estudos avaliando soluções com diferentes concentrações de Guaçatonga e suas aplicações em diferentes fases do processo cicatricial, além de, sobretudo, a avaliação dos aspectos histopatológicos da cicatrização sob tratamento com Casearia sylvestris Sw. são ainda necessários para melhorar o entendimento e trazer maiores esclarecimentos sobre os benefícios do uso deste fitoterápico. 


\section{REFERÊNCIAS}

ALBANO, M. N.et al. Anti-inflammatory and antioxidant properties of hydroalcoholic crude extract from Casearia sylvestris Sw. (Salicaceae). Journal of Ethnopharmacology, v. 147, p. 612-617, 2013.

AMENI, A.Z.et al. Toxicity study about a medicinal plant Casearia sylvestris: A contribution to Brazilian Unified Health System (SUS). Journal of Ethnopharmacology, v. 175, p. 9-13, 2015.

BEHEREGARAY, W. K.et al. Eletroestimulação na cicatrização de feridas cutâneas experimentais em coelhos. Ciência Rural, v. 44, n. 5, p. 878-883, 2014.

BIRCHARD, S. J.; SHERDING, R. G. Manual Saunders - Clínica de Pequenos Animais. 3d. São Paulo: Roca, 2008.

FERREIRA, I. M. Corrente elétrica positiva alternada no tratamento de feridas cutâneas de camundongos. 2005. 44 f. Dissertação (Mestrado)-Universidade Federal de Uberlândia.

FERREIRA, P. M.et al. Folk uses and pharmacological properties of Casearia sylvestris: a medicinal review. Anais da Academia Brasileira de Ciências, v. 83, n. 4, p. 1373-1384, 2011.

FOSSUM, T. W. Cirurgia de pequenos animais. 3 ed. Rio de Janeiro: Elsevier, 2008. 1606 p.

KULCHETSCKI, L.; QUAQUARELLI, C.; LIMA, P. R. A Guaçatonga (Casearia Sylvestris Sw.) e seu pontencial como fitoterápico: Um resultado prático de trabalho extencionista no distrito de Itaiacoca. Revista Conexão UEPG, v. 1, n. 1, p. 16-22, 2006.

LIPINSKI, L. C. Comparação da atividade cicatrizante na pele bovina entre fitoterapicos de uso tópico. 2008. 63 f. Dissertação (Mestrado) - Universidade Federal do Paraná, Curitiba.

MARCHINI, F. B.et al. Efeito do óleo de rosa mosqueta na cicatrização de feridas abertas. Revista Paulista de Medicina, v. 106, n. 6, p. 356, 1988.

MATTOS, E. Set al. Evaluation of antinociceptive activity of Casearia sylvestris and possible mechanism of action. Journal of Ethnopharmacology, v. 112, p. 1-6, 2007.

PAVLETIC, M. M. Atlas of Small animal wound managemet and reconstructive surgery. 3ed. Iowa: Wiley- Blackwell, 2010.

SASSIOTO, M. C. P.et al. Efeito da Casearia sylvestris no reparo ósseo com matriz óssea bovina desvitalizada em ratos. Acta Cirúrgica Brasileira, v. 19, n. 6, p. 637-641, 2004.

TEVES, D. C.; CABRAL, A. C. V.; SIMÕES, M. J.; KULAY, J. R. L. Biologia da reparação tecidual. Jornal Brasileiro de Medicina, v. 50 n. 5, p. 39-44, 1986.

TORRES, R. B.; YAMAMOTO, K. Taxonomia de espécie de Casearia Jacq. (Flacourtiaceae) do estado de São Paulo. Revista Brasileira de Botânica, v. 9, p. 239-258, 1986.

WALDRON, D. R.; TREVOR, P. Management of superficial skin wounds. In: SLATTER, D. S. Textbook of small animal surgery. 2 ed. Philadelphia: Saunders, 1993. p. 269-280.

WERLE, A. L. B.et al. Avaliação da atividade de Casearia Sylvestris Swartz (Flacourtiaceae) sobre os níveis séricos de triglicerídeos em ratos. Revista Brasileira de Farmacognosia, v. 19, n. 2, p. 400-402, 2009. 